\title{
Asthma symptoms associated with depression and lower quality of life: a population survey
}

\author{
Robert D Goldney, Richard Ruffin, Laura J Fisher and David H Wilson
}

ASTHMA IS AN IMPORTANT national health priority because of its high and increasing prevalence, high morbidity and mortality, and direct and indirect costs. Representative population surveys of adult asthma have put the prevalence at $12 \%$ of the population ${ }^{1}$ with significant impact on quality of life. ${ }^{2}$ Furthermore, the cost of asthma has been equated with that of higher profile conditions, such as cardiovascular disease, ${ }^{3,4}$ with much of this being attributed to the severe end of the asthma spectrum. ${ }^{4,5}$ It is also at this end of the spectrum that asthma has been associated with significant comorbidities, especially depression. ${ }^{6-10}$

Apart from a randomly selected telephone survey sample in California, ${ }^{6}$ most of the studies that have investigated depression as a comorbidity of asthma have been drawn from hospital ${ }^{7}$ or general practice populations, ${ }^{8}$ or from specific subgroups such as patients with chronic illnesses in the American Medical Outcomes Study, ${ }^{8}$ or military personnel. ${ }^{10}$ While these studies highlight the problem, the generalisability of their findings to the broader asthma population is limited.

Evidence-based decisions about asthma and depression that will inform health policy and intervention are best made from population samples that identify prevalence rates of asthma, describe problem subgroups and related phenomena, and estimate the potential for improved health outcomes.

In this study we aimed to assess asthma, depression and quality of life in a representative population sample. More specifically, we aimed to investigate the relationship between depression and known correlates of asthma

\section{ABSTRACT}

Objective: To identify any association between asthma and depression and quality of life.

Design and setting: A face-to-face Health Omnibus Survey of a random and representative sample of the South Australian population in August 1998.

Participants: 3010 randomly selected participants aged 15 years and over.

Main outcome measures: Prevalence of doctor-diagnosed asthma, and scores for depression (measured by PRIME-MD instrument) and quality of life (measured by SF-36) in affected participants.

Results: The prevalence of asthma was $9.9 \%$. The prevalence of major depression was significantly higher for those who experienced dyspnoea, wakening at night with asthma, and morning symptoms of asthma. Quality-of-life scores were also lower for the same groups.

Conclusions: Depression is a serious but potentially remediable comorbidity with asthma that may affect appropriate diagnosis and outcome.

MJA 2003; 178: 437-441

severity, including nocturnal symptoms, ${ }^{11,12}$ morning symptoms of wheeze, ${ }^{12}$ number of hospital admissions, ${ }^{13,14}$ use of preventer medication, ${ }^{15}$ and days lost from work. ${ }^{16}$ Such information may guide not only clinical management of asthma, but also public health policy of this national health priority area, thereby enhancing quality of life for people with asthma.

\section{METHODS}

The data used in this study were obtained from the 1998 South Australian Health Omnibus Survey. This is an annual face-to-face population survey of the South Australian population and has operated each year at the same time since 1990, with consistent survey methods which have been described in detail elsewhere. ${ }^{17}$ Data were weighted to the nearest available (1996) Census

\footnotetext{
University of Adelaide, Adelaide, SA.

Robert D Goldney, MD, FRANZCP, Professor, Department of Psychiatry; Richard Ruffin, MD, FRACP, Mitchell Professor of Medicine, Department of Medicine; David H Wilson, MPH, PhD, Associate Professor, Department of Medicine.

The Adelaide Clinic, Adelaide, SA

Laura J Fisher, BA(Hons), Research Officer, The Adelaide Clinic.

Reprints will not be available from the authors. Correspondence: Professor Robert D Goldney, The Adelaide Clinic, 33 Park Terrace, Gilberton, SA 5081. robert.goldney@adelaide.edu.au
}

data to provide estimates that were representative of the South Australian population. Formal approval was granted by the Health Omnibus Survey Steering Committee of South Australia.

To determine doctor-diagnosed asthma, participants were asked if they had ever had asthma, whether a doctor confirmed their asthma, and if they still had asthma. If they answered yes to all these questions, they were asked about indicators of asthma severity:

- How often do you waken during the night with asthma?;

- In the last 12 months have you had any hospital admissions for asthma where you stayed for at least one night?; and

- In the last 12 months have you had any days lost from work, school or home duties from asthma?

The dyspnoea dimension of the Asthma Quality of Life Questionnaire ${ }^{18}$ was used to determine dyspnoea. Participants were also asked if they used preventer medication regularly, and whether they wakened in the morning with other symptoms. Demographic questions were also asked (age, sex, marital status, area of residence, country of birth, educational qualifications and income). 


1: Predictors of asthma determined by logistic regression
\begin{tabular}{lcc} 
Variable & Odds ratio $(\mathbf{9 5} \% \mathbf{C l})$ & $\boldsymbol{P}$ \\
\hline Female sex & $1.55(1.22-1.99)$ & 0.003 \\
Depression & $1.40(1.04-1.88)$ & 0.026 \\
Australian born & $1.60(1.18-2.18)$ & 0.003
\end{tabular}

\section{2: Prevalence of major or all types of depression for those with or without each asthma symptom}

\begin{tabular}{|c|c|c|}
\hline \multirow[b]{2}{*}{ Asthma severity indicator } & \multicolumn{2}{|c|}{ Prevalence } \\
\hline & Major depression $(n=43)$ & All depression $(n=66)$ \\
\hline \multicolumn{3}{|l|}{ Dyspnoea } \\
\hline Yes $(n=43)$ & $32.6 \% *(14 / 43)$ & $44.2 \% *(19 / 43)$ \\
\hline No $(n=257)$ & $11.3 \%(29 / 257)$ & $17.9 \%(46 / 257)$ \\
\hline \multicolumn{3}{|l|}{ Wakening at night } \\
\hline Yes $(n=38)$ & $34.2 \% *(13 / 38)$ & $47.4 \% *(18 / 38)$ \\
\hline No $(n=261)$ & $11.5 \%(30 / 261)$ & $18.4 \%(48 / 261)$ \\
\hline \multicolumn{3}{|l|}{ Preventer medication } \\
\hline Yes $(n=202)$ & $16.3 \%(33 / 202)$ & $22.8 \%(46 / 202)$ \\
\hline No $(n=95)$ & $10.5 \%(10 / 95)$ & $18.9 \%(18 / 95)$ \\
\hline \multicolumn{3}{|l|}{ Morning symptoms } \\
\hline Yes $(n=108)$ & $25.0 \% *(27 / 108)$ & $35.2 \% *(38 / 108)$ \\
\hline No $(n=191)$ & $8.4 \%(16 / 191)$ & $14.1 \%(27 / 191)$ \\
\hline \multicolumn{3}{|c|}{ Days lost from normal activities } \\
\hline Yes $(n=57)$ & $19.3 \%(11 / 57)$ & $28.1 \%(16 / 57)$ \\
\hline No $(n=242)$ & $13.2 \%(32 / 242)$ & $20.7 \%(50 / 242)$ \\
\hline \multicolumn{3}{|c|}{ Hospitalised in the last 12 months } \\
\hline Yes $(n=15)$ & $13.3 \%(2 / 15)$ & $20.0 \%(3 / 15)$ \\
\hline No $(n=285)$ & $14.4 \%(41 / 285)$ & $22.1 \%(63 / 285)$ \\
\hline
\end{tabular}

Depression was assessed by means of the PRIME-MD questionnaire, which has been validated to provide estimates of mental disorder comparable with those found using structured and longer diagnostic interviews. ${ }^{19}$ In the analyses of this study, the categories of major depressive disorder, dysthymia, minor depressive disorder and bipolar disorder were collapsed to provide estimates of major depression and all depression.

The Short-Form-36 (SF-36), a health-related quality-of-life questionnaire was also included to assess the quality of life associated with the different asthma severity indicators. The SF36 has been validated for use in Australia, ${ }^{20}$ and norms were calculated for the South Australian population for comparison with each of the asthma severity indicators. The SF-36 com- prises 36 questions which measure eight dimensions of health: physical functioning, role limitations due to physical health, bodily pain, general health, vitality, social functioning, role limitations due to emotional health, and mental health. In addition, physical and mental component summary scales can be derived.

\section{Statistical analyses}

Data were analysed using the Statistical Package for the Social Sciences (SPSS) $^{21}$ and EpiInfo. ${ }^{22}$ The variables of age, sex, depression, body mass index, education, and migrant, work, income and relationship status, were included in a univariate analysis in which odds ratios were calculated. Variables that were statistically significant at the univariate stage were then included in a logistic regression analysis. A series of multiple analysis of variance (MANOVA) analyses was conducted to examine the relationship between each asthma severity indicator and SF-36 dimension. The MUPLUS procedure was used to produce weighted means for each symptom variable, controlling for age and sex. ${ }^{23}$ Mean SF-36 scores were compared using $t$ tests.

Standard scores were calculated for both the physical and mental health components summary scales of the SF-36 by dividing the difference between the quality-of-life scores for each symptom severity indicator and the norm of the South Australian population by the standard deviation of the South Australian population. ${ }^{24}$

\section{RESULTS}

From the 4400 households selected, 111 were found to be vacant dwellings. From the remaining 4289 dwellings, 3010 interviews were conducted (70.2\% response rate). Non-response was due to refusal (658), contact not being established after six visits (408), language barrier (73), the selected respondent being absent for the duration of the survey (71) and illness (69).

The mean age of respondents was 43.9 years (95\% CI, 43.2-44.5). There were 1464 males (48.7\%) and 1546 females $(51.4 \%)$. The population point prevalence of asthma in this study was $9.9 \%$ (299 of the 3010 participants; 95\% CI, 8.8\%-11.0\%). Box 1 shows the demographic variables that were significantly associated with asthma after logistic regression analysis were migrant status, sex and all depression.

Box 2 shows that there were statistically significant increases in major depression associated with dyspnoea, wakening at night and morning symptoms for those with these asthma severity indicators compared with those without them. There was also a statistically significantly higher rate of major depression among those with asthma (14.4\% [43/ 299]) compared with those without asthma (5.7\% [154/2711]; $P=0.000)$. This was also the case for all depression, with a rate of $22.1 \%(66 / 299)$ among those with asthma compared with 


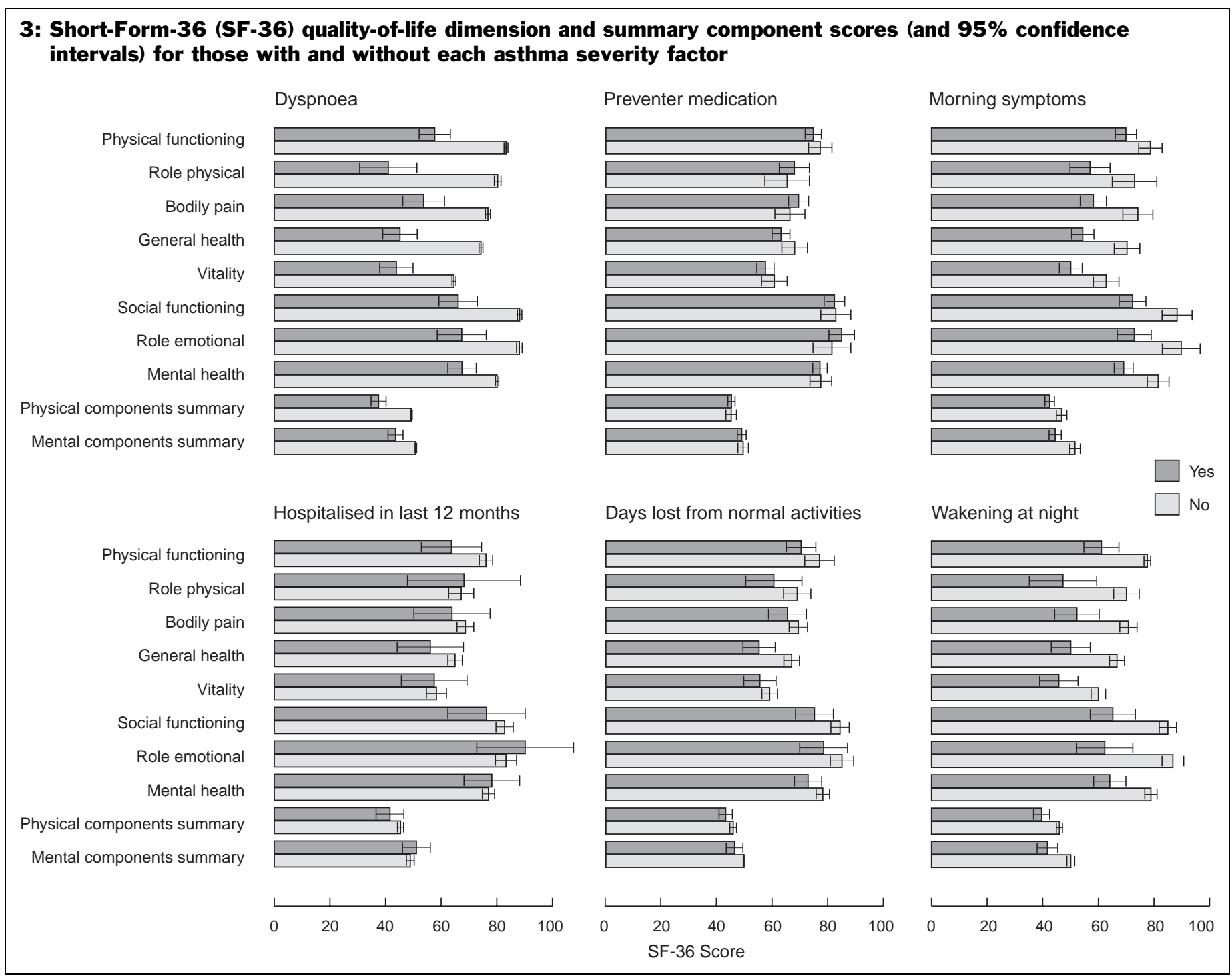

$16.7 \%$ (452/2711) among those without asthma $(P=0.03)$. We did not compare depression rates across the asthma severity variables because they are not independent groups.

Box 3 shows that dyspnoea, wakening at night, and morning symptoms also have greatest impact on reducing quality-of-life scores for all of the SF-36 dimensions $(P<0.01)$. Of interest is the observation that hospital admissions are associated with lower scores of three physical health dimensions (physical functioning, bodily pain and general health) and social functioning $(P<0.01)$. Wakening at night, days lost from usual activities, morning symptoms and dyspnoea were also associated with significantly lower quality-of-life scores on the SF-36 mental and physical health components summaries.
Box 4 compares the SF-36 physical and mental components summary for the asthma severity indicators standardised to South Australian population norms. An effect size of 0.2 (or a fifth) of a standard deviation is described as small or mild; an effect size of 0.5 is described as moderate; and an effect size of 0.8 or greater as large. ${ }^{25}$ There was a large effect on quality of life for wakening at night and dyspnoea, a moderate effect for days lost from normal activities, hospital admission in the last 12 months and morning symptoms, and a small effect for use of preventer medications.

\section{DISCUSSION}

There is no doubt that asthma is significantly associated with depressive disor- ders. Furthermore, three specific symptoms - dyspnoea, wakening at night with asthma symptoms, and morning symptoms - are particularly strongly associated with depression. There was also a significant and clinically important impact on the quality of life of those who reported wakening at night, morning symptoms and dyspnoea. This effect was at least doubled for both the physical and mental health quality-of-life dimensions when compared with the other indicators of asthma severity.

Our findings are consistent with those of other studies, ${ }^{6-10}$ but go further by specifically delineating the strong relationship between depression, asthma severity indicators and quality of life in a random and representative community sample. 


\section{4: Effect of asthma severity factors on the Short-Form-36 (SF-36) physical and mental health components summary scores*}

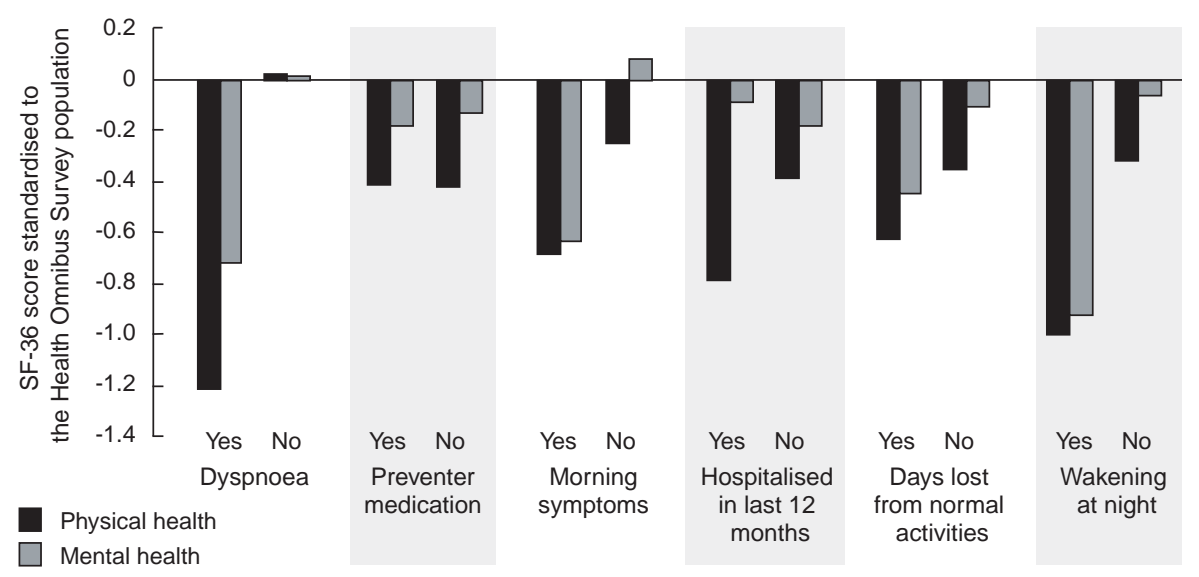

* For 299 patients with asthma; data standardised against that for the 3010 patients interviewed in the 1998 South Australian Health Omnibus Survey.

The comorbidity of asthma and depression challenges clinicians to evaluate patients carefully, as wakening at night, a diurnal mood variation with symptoms that are worse in the morning, and dyspnoea as part of associated anxiety and agitation can also be symptoms of depression. ${ }^{26}$

There are potential limitations to this study. The presence of asthma was detemined from patient self-report, as was the presence of asthma severity indicators, and no quantification of pulmonary function was available. Similarly, depression was detected on the basis of responses to a standard checklist of symptoms presented by a trained health interviewer, rather than a clinician. Nevertheless, our findings for the prevalence of asthma and depression were within the range of other epidemiological studies. ${ }^{6,27}$

It is pertinent to consider how depression may affect asthma management. It has been shown that, in problem solving, patients with depression were less able to narrow down the possible range of solutions to a problem and persevered with unconfirmed solutions, ${ }^{28}$ and depression has been associated with impaired decision making and poor performance on more complex tasks. ${ }^{29}$ There are also documented effects of depression on memory, ${ }^{30}$ attention ${ }^{31}$ and decision making. All of these cognitive mechanisms are involved in patient compliance with treatment, and are therefore relevant in self-management plans and expected management outcomes. ${ }^{32}$ Serious deficiencies in making decisions to seek medical help or call an ambulance have been reported in cases of a slow-onset asthma attack. ${ }^{33}$ This report also noted serious discrepancies in terms of patient knowledge of their asthma; even patients who had a reasonable idea of what to do in an asthma attack were frequently unable to put their knowledge into practice when necessary, leading to life-threatening situations. It is possible that emotional factors, including depression, may have influenced such behaviour, and further studies targeting this depression in asthma are indicated. Indeed, our findings support the conclusion of one study of depressive symptoms and outcome in asthma that, "these relatively unexplored patient-centered variables in asthma are potentially modifiable and may offer new ways to intervene and improve asthma outcomes". ${ }^{7}$

Our results, from a random and representative population sample, rather than a clinical sample, show not only the important comorbidity of depression with asthma, but also confirm the previously acknowledged severity symptoms of asthma and their impact on quality of life. However, those severity symptoms are often associated with depression, and therefore asthma guide- lines need to consider depression in diagnosis and management to improve outcome. While it is correctly stated in the National Asthma Campaign Guidelines $^{3,4}$ that caution should be exercised in the use of sedatives, it is noteworthy that no mention is made of the potential value of antidepressant measures, including medication, as these data suggest that they may have an important role to play.

\section{COMPETING INTERESTS}

R Goldney and R Ruffin have previously accepted honoraria from a number of pharmaceutical companies producing medications for the treatment of asthma and antidepressant medications for participation on advisory boards and in educational programs.

\section{ACKNOWLEDGEMENTS}

Analysis of these data was supported by grants from Wyeth Australia Pty Ltd. and Pfizer Pty Ltd. These companies had no role in the study design, data collection, interpretation or publication of the results.

\section{REFERENCES}

1. Ruffin R, Wilson D, Smith B, et al. Prevalence, morbidity and management of adult asthma in South Australia. Immunol Cell Biol 2001; 79: 191-194.

2. Adams R, Wakefield M. Quality of life in asthma: a comparison of community and hospital asthma patients. J Asthma 2001; 38: 205-214.

3. National Asthma Campaign 2000. Asthma management handbook. Melbourne: National Asthma Council, 2002.

4. National Asthma Campaign. Report on the costs of asthma in Australia. Available at: http://nationalasthma.org.au/publications/costs/costindx.html (accessed Aug 2002).

5. Serra-Batlles J, Plaza V, Morejun E, et al. Costs of asthma according to degree of severity. Eur Respir J 1998; 12 1322-1326

6. Von Behren J, Kreutzer R, Hernandez A. Self-reported asthma prevalence in adults in California. Asthma 2002; 39: 429-440

7. Mancuso CA, Rincon M, McCulloch CE, Charlson ME. Selfefficacy, depressive symptoms, and patients' expectation predict outcomes in asthma. Med Care 2001; 39: 13261338.

8. Rimington LD, Davies DH, Lowe D, Pearson MG. Relationship betweeen anxiety, depression, and morbidity in adult asthma patients. Thorax 2001; 56: 266-271.

9. Manocchia M, Keller S, Ware JE. Sleep problems, healthrelated quality of life, work functioning and health care utilisation among the chronically ill. Qual Life Res 2001; 10: 331-345.

10. Young SY, Gunzenhauser JD, Malone KE, McTiernan A. Body mass index and asthma in the military population of the northwestern United States. Arch Intern Med 2001. 161: 1605-1611.

11. Fix $A$, Sexton $M$, Langenberg $P$, et al. The association of nocturnal asthma with asthma severity. J Asthma 1997; 34: 329-336

12. Colice GL, Burgt JV, Song J, et al. Categorising asthma severity. Am J Respir Crit Care Med 1999; 160: 1962-1967.

13. Ten Brinke A, Ouwerekerk ME, Zwinderman AH, et al. Psychopathology in patients with severe asthma is associated with increased health care utilization. Am J Respir Crit Care Med 2001; 163: 1093-1096.

14. Marks GB, Heslop W, Yates DH. Prehospital managemen of exacerbations of asthma: relation to patient and disease characteristics. Respirology 2000; 5: 45-50.

15. Cluley S, Cochrane GM. Psychological disorder in asthma is associated with poor control and poor adherence to inhaled steroids. Respir Med 2001; 95: 37-39. 
16. Campbell DA, Yellowlees PM, McLennan G, et al. Psychiatric and medical features of near fatal asthma. Thorax 1995 50: 254-259

17. Wilson DH, Wakefield M, Taylor AW. The South Australian Health Omnibus Survey. Health Promotion J Aust 1992; 2 47-49.

18. Marks GB, Dunn SM, Woolcock AJ. A scale for the measurement of quality of life in adults with asthma. J Clin Epidemiol 1992; 45: 461-472.

19. Spitzer RL, Williams JB, Kroenke K, et al. Utility of a new procedure for diagnosing mental disorders in primary care. The PRIME-MD study. JAMA 1994; 272: 1749-1756.

20. McCallum J. The SF-36 in an Australian sample: validating a new generic health status measure. Aust $J$ Public Health 1995; 19: 160-166.

21. SPSS for Windows. Release 10.0. Chicago: SPSS Inc 2001.

22. Dean AG, Dean JA, Coulombier D, et al. Epi Info Version 6 : A word processing, data base, and statistics program for epidemiology on microcomputers. Atlanta GA: Centers for Disease Control and Prevention, 1994.

23. Hosmer DW, Lemeshow S. Applied logistic regression. New York: John Wiley \& Sons, 1989

24. Garrat AM, Ruta DA, Abdalla MI, et al. The SF-36 health survey questionnaire: an outcome measure suitable for routine use within the NHS. BMJ 1993; 306: 1440-1444.

25. Kazis LE, Anderson JJ, Mennan RF. Effect sizes for interpreting changes in health status. Med Care 1989; 27 (3 Suppl): S178-S189.

26. Diagnostic and statistical manual of mental disorders. fourth edition, text revision. Washington: American Psychiatric Association, 2000.

27. Angst J. The prevalence of depression. In: Briley M, Montgomery S, editors. Antidepressant therapy at the dawn of the third millennium. London: Martin Dunitz, 1998 191-212.

28. Silberman EK, Weingartner H, Post RM. Thinking disorder in depression. Arch Gen Psychiatry 1983; 40: 775-780.

29. Tarbuck AF, Paykel ES. Effects of depression on the cognitive function of young and older subjects. Psycho Med 1995; 25: 285-295.

30. Rubinstein JS, Michael A, Paykel ES, Sahakian BJ. Cognitive impairment in remission of bipolar affective disorders. Psychol Med 2000; 30: 1025-1036.

31. Lemelin S, Baruch $P$, Vincent $A$, et al. Attention disturbance in clinical depression. Deficient distraction inhibition or processing resource deficit. J Nerv Ment Dis 1996; 184 114-121.

32. Gibson PG, Coughlan J, Wilson AJ, et al. Limited (information only) patient education programs for adults with asthma. In: The Cochrane Library, Issue 4, 2001. Oxford: Update Software.

33. Kolbe J, Vamos M, Fergusson W, et al. Differential influences on asthma self-management knowledge and selfmanagement behaviour in acute severe asthma. Chest 1996; 110: 1463-1468.

(Received 16 Sep 2002, accepted 10 Feb 2003)

\section{Correction}

Re: "Does a combined program of dietary modification and physical activity or the use of metformin reduce the conversion from impaired glucose tolerance to type 2 diabetes?", the EBM: Trials on Trial article by Dorothy E M Mackerras in the 7 April issue of the Journal (Med F Aust 2003; 178: 346-347), in which the title was incorrect. The title should have been "Does dietary modification and/or physical activity reduce the progression from impaired glucose tolerance to type 2 diabetes?". The article by Dr Mackerras that also dealt with metformin was published in the

17 February issue.

\section{books received}

The 5-minute herb and dietary supplement consult. Fugh-Berman A. Philadelphia: Lippincott Williams and Wilkins, 2003 ( $x v+475$ pp \$132) ISBN 0683302736 Alcohol and the developing world: a public health perspective. Room R, Jernigan $D$, Carlini-Marlatt B, Gureje O, Makela K, Marshall M, Medina-Mora ME, Monteiro M, Parry C, Partanen J, Riley L, Saxena S. Helsinki: Finnish Foundation for Alcohol Studies and World Health Organization, 2002 (276 pp \$33.10) ISBN 9519192638.

Analytical neurology: examining the evidence for clinical practice. Benatar M. Amsterdam:

Butterworth-Heinemann, 2003 (xvi + 328 pp \$86.90) ISBN 0750674407.

Atlas of travel medicine and health. Chiodini JBL. Hamilton ONT: BC Decker, 2003 (vii + $136 \mathrm{pp}+$ CDROM \$131.30) ISBN 1550091891

Bennett and Elliott's Physiology and medicine of diving. Brubakk AO, Neuman TS (eds). Edinburgh: Saunders, 2003 (xii + 779 pp \$319) ISBN 0702025712.

Eating disorders. How to have real control. Brigham S. Sydney: Australian Women's Weekly health series, 2003 (96 pp \$12.95) ISBN 1876624884

Ethical choices in long-term care: what does justice require? Geneva: World Health Organization, 2002 (xii + 91 pp \$22.75) ISBN 9291562285

Ethics and evidence-based medicine.

Fallibility and responsibility in clinical science. Goodman KW. Cambridge: Cambridge University Press, 2003 (xii + 168 pp \$69.95) ISBN 052176539

Exotic viral diseases. A global guide. Berger SA, Calisher $\mathrm{CH}$, Keystone JS. Hamilton ONT: BC Decker, 2003 (xii + 252 pp + CDROM \$71.50) ISBN 1550092057.

Fatigue. Krupp LB. Philadelphia: Butterworth Heinemann, 2003 (ix + 246 pp \$55) ISBN 075067038X.

Headaches. Relief at last. Gressor M. Sydney: Australian Women's Weekly health series, 2003 (96 pp \$12.95) ISBN 1876624922.

Helminth control in school-age children. A guide for managers of control programmes. Montresor A, Crompton DWT, Gyorkos TW, Saviolo L. Geneva: World Health

Organization, 2002 (viii + 64 pp \$33.85) ISBN 9241545569

Insomnia. How to sleep easy. Lack L, Wright H, Bearpark H. Sydney: Australian Women's Weekly health series, 2003 (96 pp \$12.95) ISBN 1876624965.

Irritable bowel syndrome. Ellard K. Sydney: Australian Women's Weekly health series, 2003 (96 pp \$12.95) ISBN 1876624973.

Journeys in healing. How others have triumphed over disease and disability.
Matthews S. Sydney: Finch, 2003 (vi + 250 pp \$24.95) ISBN 1876451424

Mosby's color atlas and text of diabetes and endocrinology. Belchetz P, Hammond PJ.

Edinburgh: Mosby, 2003 (viii + 419 pp \$115.50) ISBN 0723431043

Practical chemotherapy. A multidisciplinary approach. Summerhayes M, Daniels S. Abingdon: Radcliffe Medical, 2003 (xv + 398 pp \$104.75) ISBN 1857759656

Practical general practice. Guidelines for effective clinical management. Khot A, Polmear A (eds). London: ButterworthHeinemann, 2003 (xvii + 509 pp + CDROM $\$ 145.20)$ ISBN 0750649119 .

Providing global public goods. Managing globalization. Kaul I, Conceicao P, Le Goulven K, Mendoza RU (eds). New York: Oxford University Press, 2003 (xxii + 646 pp \$58.20) ISBN 0195157419

Success in Africa: the Onchocerciasis Control Programme in West Africa, 1974-2002. Geneva: World Health Organization, 2002 (vii + 72 pp \$33.90) ISBN 9241562277

Summary measures of population health. Concepts, ethics, measurement and applications. Murray CJL, Salomon JA, Mathers CD, Lopez AD (eds). Geneva: World Health Organization, 2002 (xxviii +770 pp \$75) ISBN 92415455181.

Tropical health in the Top End. An introduction for health practitioners. Darwin: Top End Division of General Practice, 2003 (164 pp \$42.50) ISBN 1877021024

Urology secrets. Resnick MI, Novick AC. Philadelphia: Hanley and Belfus, 2003 (xv + 341 pp \$99.09) ISBN 1560535105. Vaccines and biologicals. WHO vaccinepreventable diseases: monitoring system, 2002 global summary. Geneva: World Health Organization, 2002 (vii + 380 pp + CDROM electronic copy available from http:// www.who.int/vaccines-documents/DoxGen/ H3DoxNew.htm) ISBN none.

Vital essence. Understanding the lymphatic system in health and disease. Lymphoedema. Piller N. Adelaide: Flinders University, 2002 (1 CD ROM \$88) ISBN none.

Whiplash and other useful illnesses. Malleson A. Montreal: McGill-Queen's University Press, 2002 (viii + 527 pp \$62.95) ISBN

0773523332

WHO manual of diagnostic imaging.

Radiographic anatomy and interpretation of the musculoskeletal system. Ostensen $\mathrm{H}$, Pettersson H (eds). Geneva: World Health Organization, 2002 (vi + 203 pp \$95.20) ISBN 9241545550

WHO monographs on selected medicinal plants. Vol 2. Geneva: World Health Organization, 2002 ( $v+355$ pp \$146.35) ISBN 9241545372. 


\title{
Asthma symptoms associated with depression and lower quality of life: a population survey
}

\author{
Robert D Goldney, Richard Ruffin, Laura J Fisher and David H Wilson
}

ASTHMA IS AN IMPORTANT national health priority because of its high and increasing prevalence, high morbidity and mortality, and direct and indirect costs. Representative population surveys of adult asthma have put the prevalence at $12 \%$ of the population ${ }^{1}$ with significant impact on quality of life. ${ }^{2}$ Furthermore, the cost of asthma has been equated with that of higher profile conditions, such as cardiovascular disease, ${ }^{3,4}$ with much of this being attributed to the severe end of the asthma spectrum. ${ }^{4,5}$ It is also at this end of the spectrum that asthma has been associated with significant comorbidities, especially depression. ${ }^{6-10}$

Apart from a randomly selected telephone survey sample in California, ${ }^{6}$ most of the studies that have investigated depression as a comorbidity of asthma have been drawn from hospital ${ }^{7}$ or general practice populations, ${ }^{8}$ or from specific subgroups such as patients with chronic illnesses in the American Medical Outcomes Study, ${ }^{8}$ or military personnel. ${ }^{10}$ While these studies highlight the problem, the generalisability of their findings to the broader asthma population is limited.

Evidence-based decisions about asthma and depression that will inform health policy and intervention are best made from population samples that identify prevalence rates of asthma, describe problem subgroups and related phenomena, and estimate the potential for improved health outcomes.

In this study we aimed to assess asthma, depression and quality of life in a representative population sample. More specifically, we aimed to investigate the relationship between depression and known correlates of asthma

\section{ABSTRACT}

Objective: To identify any association between asthma and depression and quality of life.

Design and setting: A face-to-face Health Omnibus Survey of a random and representative sample of the South Australian population in August 1998.

Participants: 3010 randomly selected participants aged 15 years and over.

Main outcome measures: Prevalence of doctor-diagnosed asthma, and scores for depression (measured by PRIME-MD instrument) and quality of life (measured by SF-36) in affected participants.

Results: The prevalence of asthma was $9.9 \%$. The prevalence of major depression was significantly higher for those who experienced dyspnoea, wakening at night with asthma, and morning symptoms of asthma. Quality-of-life scores were also lower for the same groups.

Conclusions: Depression is a serious but potentially remediable comorbidity with asthma that may affect appropriate diagnosis and outcome.

MJA 2003; 178: 437-441

severity, including nocturnal symptoms, ${ }^{11,12}$ morning symptoms of wheeze, ${ }^{12}$ number of hospital admissions, ${ }^{13,14}$ use of preventer medication, ${ }^{15}$ and days lost from work. ${ }^{16}$ Such information may guide not only clinical management of asthma, but also public health policy of this national health priority area, thereby enhancing quality of life for people with asthma.

\section{METHODS}

The data used in this study were obtained from the 1998 South Australian Health Omnibus Survey. This is an annual face-to-face population survey of the South Australian population and has operated each year at the same time since 1990, with consistent survey methods which have been described in detail elsewhere. ${ }^{17}$ Data were weighted to the nearest available (1996) Census

\footnotetext{
University of Adelaide, Adelaide, SA.

Robert D Goldney, MD, FRANZCP, Professor, Department of Psychiatry; Richard Ruffin, MD, FRACP, Mitchell Professor of Medicine, Department of Medicine; David H Wilson, MPH, PhD, Associate Professor, Department of Medicine.

The Adelaide Clinic, Adelaide, SA

Laura J Fisher, BA(Hons), Research Officer, The Adelaide Clinic.

Reprints will not be available from the authors. Correspondence: Professor Robert D Goldney, The Adelaide Clinic, 33 Park Terrace, Gilberton, SA 5081. robert.goldney@adelaide.edu.au
}

data to provide estimates that were representative of the South Australian population. Formal approval was granted by the Health Omnibus Survey Steering Committee of South Australia.

To determine doctor-diagnosed asthma, participants were asked if they had ever had asthma, whether a doctor confirmed their asthma, and if they still had asthma. If they answered yes to all these questions, they were asked about indicators of asthma severity:

- How often do you waken during the night with asthma?;

- In the last 12 months have you had any hospital admissions for asthma where you stayed for at least one night?; and

- In the last 12 months have you had any days lost from work, school or home duties from asthma?

The dyspnoea dimension of the Asthma Quality of Life Questionnaire ${ }^{18}$ was used to determine dyspnoea. Participants were also asked if they used preventer medication regularly, and whether they wakened in the morning with other symptoms. Demographic questions were also asked (age, sex, marital status, area of residence, country of birth, educational qualifications and income). 


1: Predictors of asthma determined by logistic regression
\begin{tabular}{lcc} 
Variable & Odds ratio $(\mathbf{9 5} \% \mathbf{C l})$ & $\boldsymbol{P}$ \\
\hline Male sex & $1.55(1.22-1.99)$ & 0.003 \\
Depression & $1.40(1.04-1.88)$ & 0.026 \\
Overseas born & $1.60(1.18-2.18)$ & 0.003
\end{tabular}

\section{2: Prevalence of major or all types of depression for those with or without each asthma symptom}

\begin{tabular}{|c|c|c|}
\hline \multirow[b]{2}{*}{ Asthma severity indicator } & \multicolumn{2}{|c|}{ Prevalence } \\
\hline & Major depression $(n=43)$ & All depression $(n=66)$ \\
\hline \multicolumn{3}{|l|}{ Dyspnoea } \\
\hline Yes $(n=43)$ & $32.6 \% *(14 / 43)$ & $44.2 \% *(19 / 43)$ \\
\hline No $(n=257)$ & $11.3 \%(29 / 257)$ & $17.9 \%(46 / 257)$ \\
\hline \multicolumn{3}{|l|}{ Wakening at night } \\
\hline Yes $(n=38)$ & $34.2 \% *(13 / 38)$ & $47.4 \% *(18 / 38)$ \\
\hline No $(n=261)$ & $11.5 \%(30 / 261)$ & $18.4 \%(48 / 261)$ \\
\hline \multicolumn{3}{|l|}{ Preventer medication } \\
\hline Yes $(n=202)$ & $16.3 \%(33 / 202)$ & $22.8 \%(46 / 202)$ \\
\hline No $(n=95)$ & $10.5 \%(10 / 95)$ & $18.9 \%(18 / 95)$ \\
\hline \multicolumn{3}{|l|}{ Morning symptoms } \\
\hline Yes $(n=108)$ & $25.0 \% *(27 / 108)$ & $35.2 \% *(38 / 108)$ \\
\hline No $(n=191)$ & $8.4 \%(16 / 191)$ & $14.1 \%(27 / 191)$ \\
\hline \multicolumn{3}{|c|}{ Days lost from normal activities } \\
\hline Yes $(n=57)$ & $19.3 \%(11 / 57)$ & $28.1 \%(16 / 57)$ \\
\hline No $(n=242)$ & $13.2 \%(32 / 242)$ & $20.7 \%(50 / 242)$ \\
\hline \multicolumn{3}{|c|}{ Hospitalised in the last 12 months } \\
\hline Yes $(n=15)$ & $13.3 \%(2 / 15)$ & $20.0 \%(3 / 15)$ \\
\hline No $(n=285)$ & $14.4 \%(41 / 285)$ & $22.1 \%(63 / 285)$ \\
\hline
\end{tabular}

Depression was assessed by means of the PRIME-MD questionnaire, which has been validated to provide estimates of mental disorder comparable with those found using structured and longer diagnostic interviews. ${ }^{19}$ In the analyses of this study, the categories of major depressive disorder, dysthymia, minor depressive disorder and bipolar disorder were collapsed to provide estimates of major depression and all depression.

The Short-Form-36 (SF-36), a health-related quality-of-life questionnaire was also included to assess the quality of life associated with the different asthma severity indicators. The SF36 has been validated for use in Australia, ${ }^{20}$ and norms were calculated for the South Australian population for comparison with each of the asthma severity indicators. The SF-36 com- prises 36 questions which measure eight dimensions of health: physical functioning, role limitations due to physical health, bodily pain, general health, vitality, social functioning, role limitations due to emotional health, and mental health. In addition, physical and mental component summary scales can be derived.

\section{Statistical analyses}

Data were analysed using the Statistical Package for the Social Sciences (SPSS) $^{21}$ and EpiInfo. ${ }^{22}$ The variables of age, sex, depression, body mass index, education, and migrant, work, income and relationship status, were included in a univariate analysis in which odds ratios were calculated. Variables that were statistically significant at the univariate stage were then included in a logistic regression analysis. A series of multiple analysis of variance (MANOVA) analyses was conducted to examine the relationship between each asthma severity indicator and SF-36 dimension. The MUPLUS procedure was used to produce weighted means for each symptom variable, controlling for age and sex. ${ }^{23}$ Mean SF-36 scores were compared using $t$ tests.

Standard scores were calculated for both the physical and mental health components summary scales of the SF-36 by dividing the difference between the quality-of-life scores for each symptom severity indicator and the norm of the South Australian population by the standard deviation of the South Australian population. ${ }^{24}$

\section{RESULTS}

From the 4400 households selected, 111 were found to be vacant dwellings. From the remaining 4289 dwellings, 3010 interviews were conducted ( $70.2 \%$ response rate). Non-response was due to refusal (658), contact not being established after six visits (408), language barrier (73), the selected respondent being absent for the duration of the survey (71) and illness (69).

The mean age of respondents was 43.9 years (95\% CI, 43.2-44.5). There were 1464 males (48.7\%) and 1546 females $(51.4 \%)$. The population point prevalence of asthma in this study was $9.9 \%$ (299 of the 3010 participants; 95\% CI, 8.8\%-11.0\%). Box 1 shows the demographic variables that were significantly associated with asthma after logistic regression analysis were migrant status, sex and all depression.

Box 2 shows that there were statistically significant increases in major depression associated with dyspnoea, wakening at night and morning symptoms for those with these asthma severity indicators compared with those without them. There was also a statistically significantly higher rate of major depression among those with asthma (14.4\% [43/ 299]) compared with those without asthma (5.7\% [154/2711]; $P=0.000)$. This was also the case for all depression, with a rate of $22.1 \%(66 / 299)$ among those with asthma compared with 


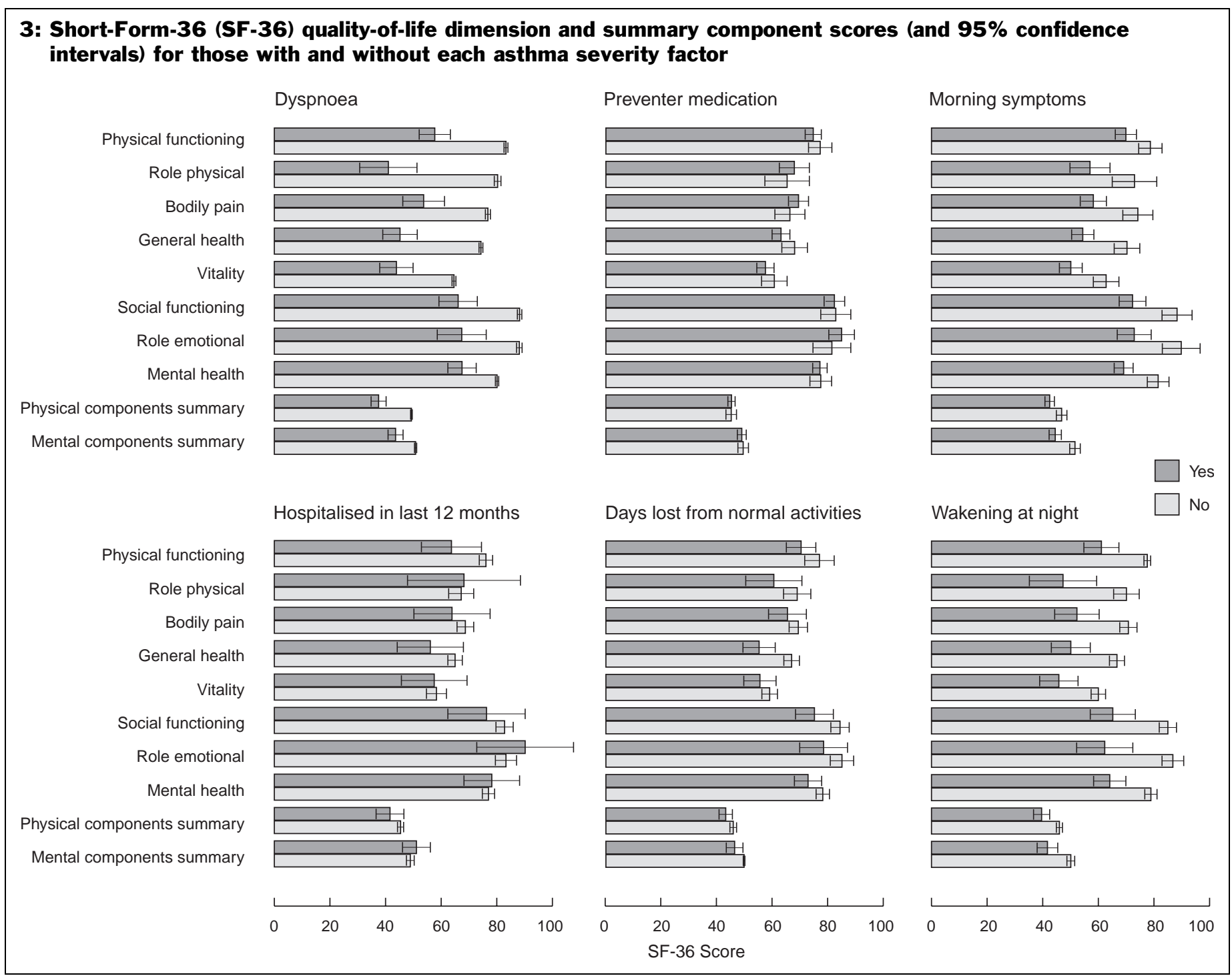

$16.7 \%$ (452/2711) among those without asthma $(P=0.03)$. We did not compare depression rates across the asthma severity variables because they are not independent groups.

Box 3 shows that dyspnoea, wakening at night, and morning symptoms also have greatest impact on reducing quality-of-life scores for all of the SF-36 dimensions $(P<0.01)$. Of interest is the observation that hospital admissions are associated with lower scores of three physical health dimensions (physical functioning, bodily pain and general health) and social functioning $(P<0.01)$. Wakening at night, days lost from usual activities, morning symptoms and dyspnoea were also associated with significantly lower quality-of-life scores on the SF-36 mental and physical health components summaries.
Box 4 compares the SF-36 physical and mental components summary for the asthma severity indicators standardised to South Australian population norms. An effect size of 0.2 (or a fifth) of a standard deviation is described as small or mild; an effect size of 0.5 is described as moderate; and an effect size of 0.8 or greater as large. ${ }^{25}$ There was a large effect on quality of life for wakening at night and dyspnoea, a moderate effect for days lost from normal activities, hospital admission in the last 12 months and morning symptoms, and a small effect for use of preventer medications.

\section{DISCUSSION}

There is no doubt that asthma is significantly associated with depressive disor- ders. Furthermore, three specific symptoms - dyspnoea, wakening at night with asthma symptoms, and morning symptoms - are particularly strongly associated with depression. There was also a significant and clinically important impact on the quality of life of those who reported wakening at night, morning symptoms and dyspnoea. This effect was at least doubled for both the physical and mental health quality-of-life dimensions when compared with the other indicators of asthma severity.

Our findings are consistent with those of other studies, ${ }^{6-10}$ but go further by specifically delineating the strong relationship between depression, asthma severity indicators and quality of life in a random and representative community sample. 


\section{4: Effect of asthma severity factors on the Short-Form-36 (SF-36) physical and mental health components summary scores*}

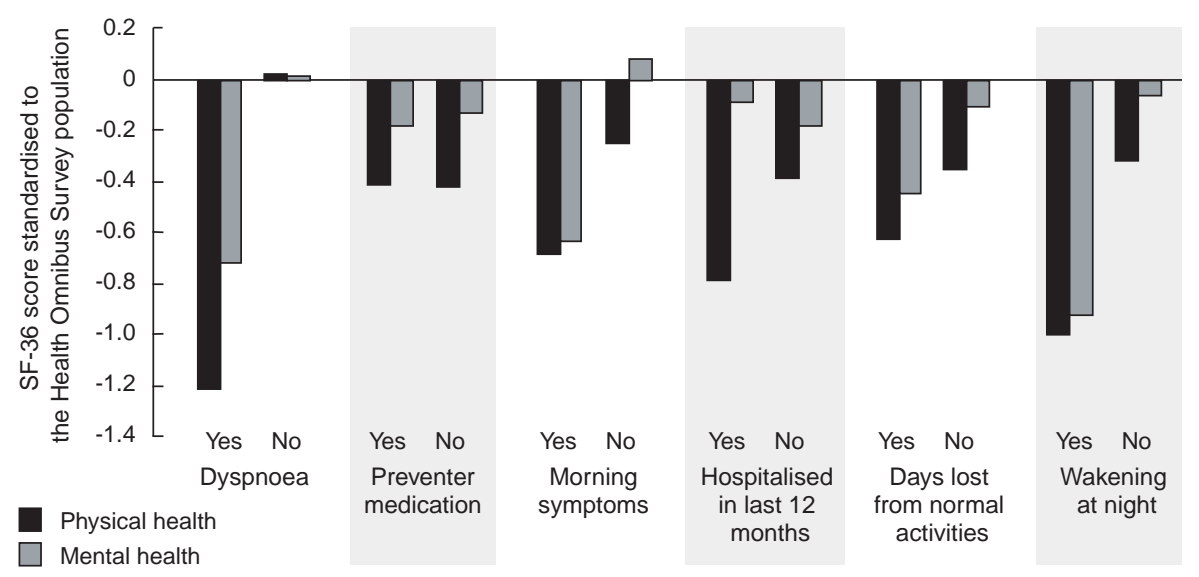

* For 299 patients with asthma; data standardised against that for the 3010 patients interviewed in the 1998 South Australian Health Omnibus Survey.

The comorbidity of asthma and depression challenges clinicians to evaluate patients carefully, as wakening at night, a diurnal mood variation with symptoms that are worse in the morning, and dyspnoea as part of associated anxiety and agitation can also be symptoms of depression. ${ }^{26}$

There are potential limitations to this study. The presence of asthma was detemined from patient self-report, as was the presence of asthma severity indicators, and no quantification of pulmonary function was available. Similarly, depression was detected on the basis of responses to a standard checklist of symptoms presented by a trained health interviewer, rather than a clinician. Nevertheless, our findings for the prevalence of asthma and depression were within the range of other epidemiological studies. ${ }^{6,27}$

It is pertinent to consider how depression may affect asthma management. It has been shown that, in problem solving, patients with depression were less able to narrow down the possible range of solutions to a problem and persevered with unconfirmed solutions, ${ }^{28}$ and depression has been associated with impaired decision making and poor performance on more complex tasks. ${ }^{29}$ There are also documented effects of depression on memory, ${ }^{30}$ attention ${ }^{31}$ and decision making. All of these cognitive mechanisms are involved in patient compliance with treatment, and are therefore relevant in self-management plans and expected management outcomes. ${ }^{32}$ Serious deficiencies in making decisions to seek medical help or call an ambulance have been reported in cases of a slow-onset asthma attack. ${ }^{33}$ This report also noted serious discrepancies in terms of patient knowledge of their asthma; even patients who had a reasonable idea of what to do in an asthma attack were frequently unable to put their knowledge into practice when necessary, leading to life-threatening situations. It is possible that emotional factors, including depression, may have influenced such behaviour, and further studies targeting this depression in asthma are indicated. Indeed, our findings support the conclusion of one study of depressive symptoms and outcome in asthma that, "these relatively unexplored patient-centered variables in asthma are potentially modifiable and may offer new ways to intervene and improve asthma outcomes". ${ }^{7}$

Our results, from a random and representative population sample, rather than a clinical sample, show not only the important comorbidity of depression with asthma, but also confirm the previously acknowledged severity symptoms of asthma and their impact on quality of life. However, those severity symptoms are often associated with depression, and therefore asthma guide- lines need to consider depression in diagnosis and management to improve outcome. While it is correctly stated in the National Asthma Campaign Guidelines $^{3,4}$ that caution should be exercised in the use of sedatives, it is noteworthy that no mention is made of the potential value of antidepressant measures, including medication, as these data suggest that they may have an important role to play.

\section{COMPETING INTERESTS}

R Goldney and R Ruffin have previously accepted honoraria from a number of pharmaceutical companies producing medications for the treatment of asthma and antidepressant medications for participation on advisory boards and in educational programs.

\section{ACKNOWLEDGEMENTS}

Analysis of these data was supported by grants from Wyeth Australia Pty Ltd. and Pfizer Pty Ltd. These companies had no role in the study design, data collection, interpretation or publication of the results.

\section{REFERENCES}

1. Ruffin R, Wilson D, Smith B, et al. Prevalence, morbidity and management of adult asthma in South Australia. Immunol Cell Biol 2001; 79: 191-194.

2. Adams R, Wakefield M. Quality of life in asthma: a comparison of community and hospital asthma patients. J Asthma 2001; 38: 205-214.

3. National Asthma Campaign 2000. Asthma management handbook. Melbourne: National Asthma Council, 2002.

4. National Asthma Campaign. Report on the costs of asthma in Australia. Available at: http://nationalasthma.org.au/publications/costs/costindx.html (accessed Aug 2002).

5. Serra-Batlles J, Plaza V, Morejun E, et al. Costs of asthma according to degree of severity. Eur Respir J 1998; 12 1322-1326

6. Von Behren J, Kreutzer R, Hernandez A. Self-reported asthma prevalence in adults in California. Asthma 2002; 39: 429-440

7. Mancuso CA, Rincon M, McCulloch CE, Charlson ME. Selfefficacy, depressive symptoms, and patients' expectation predict outcomes in asthma. Med Care 2001; 39: 13261338.

8. Rimington LD, Davies DH, Lowe D, Pearson MG. Relationship betweeen anxiety, depression, and morbidity in adult asthma patients. Thorax 2001; 56: 266-271.

9. Manocchia M, Keller S, Ware JE. Sleep problems, healthrelated quality of life, work functioning and health care utilisation among the chronically ill. Qual Life Res 2001; 10: 331-345.

10. Young SY, Gunzenhauser JD, Malone KE, McTiernan A. Body mass index and asthma in the military population of the northwestern United States. Arch Intern Med 2001. 161: 1605-1611.

11. Fix $A$, Sexton $M$, Langenberg $P$, et al. The association of nocturnal asthma with asthma severity. J Asthma 1997; 34: 329-336

12. Colice GL, Burgt JV, Song J, et al. Categorising asthma severity. Am J Respir Crit Care Med 1999; 160: 1962-1967.

13. Ten Brinke A, Ouwerekerk ME, Zwinderman AH, et al. Psychopathology in patients with severe asthma is associated with increased health care utilization. Am J Respir Crit Care Med 2001; 163: 1093-1096.

14. Marks GB, Heslop W, Yates DH. Prehospital managemen of exacerbations of asthma: relation to patient and disease characteristics. Respirology 2000; 5: 45-50.

15. Cluley S, Cochrane GM. Psychological disorder in asthma is associated with poor control and poor adherence to inhaled steroids. Respir Med 2001; 95: 37-39. 
16. Campbell DA, Yellowlees PM, McLennan G, et al. Psychiatric and medical features of near fatal asthma. Thorax 1995 50: 254-259

17. Wilson DH, Wakefield M, Taylor AW. The South Australian Health Omnibus Survey. Health Promotion J Aust 1992; 2 47-49.

18. Marks GB, Dunn SM, Woolcock AJ. A scale for the measurement of quality of life in adults with asthma. J Clin Epidemiol 1992; 45: 461-472.

19. Spitzer RL, Williams JB, Kroenke K, et al. Utility of a new procedure for diagnosing mental disorders in primary care. The PRIME-MD study. JAMA 1994; 272: 1749-1756.

20. McCallum J. The SF-36 in an Australian sample: validating a new generic health status measure. Aust $J$ Public Health 1995; 19: 160-166.

21. SPSS for Windows. Release 10.0. Chicago: SPSS Inc 2001.

22. Dean AG, Dean JA, Coulombier D, et al. Epi Info Version 6 : A word processing, data base, and statistics program for epidemiology on microcomputers. Atlanta GA: Centers for Disease Control and Prevention, 1994.

23. Hosmer DW, Lemeshow S. Applied logistic regression. New York: John Wiley \& Sons, 1989

24. Garrat AM, Ruta DA, Abdalla MI, et al. The SF-36 health survey questionnaire: an outcome measure suitable for routine use within the NHS. BMJ 1993; 306: 1440-1444.

25. Kazis LE, Anderson JJ, Mennan RF. Effect sizes for interpreting changes in health status. Med Care 1989; 27 (3 Suppl): S178-S189.

26. Diagnostic and statistical manual of mental disorders. fourth edition, text revision. Washington: American Psychiatric Association, 2000.

27. Angst J. The prevalence of depression. In: Briley $M$ Montgomery S, editors. Antidepressant therapy at the dawn of the third millennium. London: Martin Dunitz, 1998 191-212.

28. Silberman EK, Weingartner H, Post RM. Thinking disorder in depression. Arch Gen Psychiatry 1983; 40: 775-780.

29. Tarbuck AF, Paykel ES. Effects of depression on the cognitive function of young and older subjects. Psycho Med 1995; 25: 285-295.

30. Rubinstein JS, Michael A, Paykel ES, Sahakian BJ. Cognitive impairment in remission of bipolar affective disorders. Psychol Med 2000; 30: 1025-1036.

31. Lemelin S, Baruch $P$, Vincent $A$, et al. Attention disturbance in clinical depression. Deficient distraction inhibition or processing resource deficit. J Nerv Ment Dis 1996; 184 114-121.

32. Gibson PG, Coughlan J, Wilson AJ, et al. Limited (information only) patient education programs for adults with asthma. In: The Cochrane Library, Issue 4, 2001. Oxford: Update Software.

33. Kolbe J, Vamos M, Fergusson W, et al. Differential influences on asthma self-management knowledge and selfmanagement behaviour in acute severe asthma. Chest 1996; 110: 1463-1468

(Received 16 Sep 2002, accepted 10 Feb 2003)

\section{Correction}

$R e$ : "Does a combined program of dietary modification and physical activity or the use of metformin reduce the conversion from impaired glucose tolerance to type 2 diabetes?", the EBM: Trials on Trial article by Dorothy E M Mackerras in the 7 April issue of the Journal (Med F Aust 2003; 178: 346-347), in which the title was incorrect. The title should have been "Does dietary modification and/or physical activity reduce the progression from impaired glucose tolerance to type 2 diabetes?". The article by Dr Mackerras that also dealt with metformin was published in the

17 February issue.

\section{books received}

The 5-minute herb and dietary supplement consult. Fugh-Berman A. Philadelphia: Lippincott Williams and Wilkins, 2003 ( $x v+475$ pp \$132) ISBN 0683302736 Alcohol and the developing world: a public health perspective. Room $R$, Jernigan $D$ Carlini-Marlatt B, Gureje O, Makela K, Marshall M, Medina-Mora ME, Monteiro M, Parry C, Partanen J, Riley L, Saxena S. Helsinki: Finnish Foundation for Alcohol Studies and World Health Organization, 2002 (276 pp \$33.10) ISBN 9519192638.

Analytical neurology: examining the evidence for clinical practice. Benatar M. Amsterdam:

Butterworth-Heinemann, 2003 (xvi + 328 pp \$86.90) ISBN 0750674407.

Atlas of travel medicine and health. Chiodini JBL. Hamilton ONT: BC Decker, 2003 (vii + $136 \mathrm{pp}+$ CDROM \$131.30) ISBN 1550091891

Bennett and Elliott's Physiology and medicine of diving. Brubakk AO, Neuman TS (eds). Edinburgh: Saunders, 2003 (xii + 779 pp \$319) ISBN 0702025712.

Eating disorders. How to have real control. Brigham S. Sydney: Australian Women's Weekly health series, 2003 (96 pp \$12.95) ISBN 1876624884

Ethical choices in long-term care: what does justice require? Geneva: World Health Organization, 2002 (xii + 91 pp \$22.75) ISBN 9291562285

Ethics and evidence-based medicine.

Fallibility and responsibility in clinical science. Goodman KW. Cambridge: Cambridge University Press, 2003 (xii + 168 pp \$69.95) ISBN 052176539.

Exotic viral diseases. A global guide. Berger SA, Calisher $\mathrm{CH}$, Keystone JS. Hamilton ONT: BC Decker, 2003 (xii + 252 pp + CDROM \$71.50) ISBN 1550092057.

Fatigue. Krupp LB. Philadelphia: Butterworth Heinemann, 2003 (ix + 246 pp \$55) ISBN 075067038X.

Headaches. Relief at last. Gressor M. Sydney: Australian Women's Weekly health series, 2003 (96 pp \$12.95) ISBN 1876624922.

Helminth control in school-age children. A guide for managers of control programmes. Montresor A, Crompton DWT, Gyorkos TW, Saviolo L. Geneva: World Health

Organization, 2002 (viii + 64 pp \$33.85) ISBN 9241545569

Insomnia. How to sleep easy. Lack L, Wright H, Bearpark H. Sydney: Australian Women's Weekly health series, 2003 (96 pp \$12.95) ISBN 1876624965.

Irritable bowel syndrome. Ellard K. Sydney: Australian Women's Weekly health series, 2003 (96 pp \$12.95) ISBN 1876624973.

Journeys in healing. How others have triumphed over disease and disability.
Matthews S. Sydney: Finch, 2003 (vi + 250 pp \$24.95) ISBN 1876451424

Mosby's color atlas and text of diabetes and endocrinology. Belchetz P, Hammond PJ.

Edinburgh: Mosby, 2003 (viii + 419 pp \$115.50) ISBN 0723431043.

Practical chemotherapy. A multidisciplinary approach. Summerhayes M, Daniels S. Abingdon: Radcliffe Medical, 2003 (xv + 398 pp \$104.75) ISBN 1857759656

Practical general practice. Guidelines for effective clinical management. Khot A, Polmear A (eds). London: ButterworthHeinemann, 2003 (xvii + 509 pp + CDROM $\$ 145.20)$ ISBN 0750649119.

Providing global public goods. Managing globalization. Kaul I, Conceicao P, Le Goulven K, Mendoza RU (eds). New York: Oxford University Press, 2003 (xxii + 646 pp \$58.20) ISBN 0195157419

Success in Africa: the Onchocerciasis Control Programme in West Africa, 1974-2002. Geneva: World Health Organization, 2002 (vii + 72 pp \$33.90) ISBN 9241562277

Summary measures of population health. Concepts, ethics, measurement and applications. Murray CJL, Salomon JA, Mathers CD, Lopez AD (eds). Geneva: World Health Organization, 2002 (xxviii +770 pp \$75) ISBN 92415455181.

Tropical health in the Top End. An introduction for health practitioners. Darwin: Top End Division of General Practice, 2003 (164 pp \$42.50) ISBN 1877021024

Urology secrets. Resnick MI, Novick AC. Philadelphia: Hanley and Belfus, 2003 (xv + 341 pp \$99.09) ISBN 1560535105. Vaccines and biologicals. WHO vaccinepreventable diseases: monitoring system, 2002 global summary. Geneva: World Health Organization, 2002 (vii + 380 pp + CDROM electronic copy available from http:// www.who.int/vaccines-documents/DoxGen/ H3DoxNew.htm) ISBN none.

Vital essence. Understanding the lymphatic system in health and disease. Lymphoedema. Piller N. Adelaide: Flinders University, 2002 (1 CD ROM \$88) ISBN none.

Whiplash and other useful illnesses. Malleson A. Montreal: McGill-Queen's University Press, 2002 (viii + 527 pp \$62.95) ISBN

0773523332

WHO manual of diagnostic imaging.

Radiographic anatomy and interpretation of the musculoskeletal system. Ostensen $\mathrm{H}$, Pettersson H (eds). Geneva: World Health Organization, 2002 (vi + 203 pp \$95.20) ISBN 9241545550

WHO monographs on selected medicinal plants. Vol 2. Geneva: World Health Organization, $2002(v+355$ pp \$146.35) ISBN 9241545372 